\title{
ANALISIS PENGARUH KETIDAKSEIMBANGAN BEBAN TERHADAP EFISIENSI TRANSFORMATOR TIGA FASA DI PT. PLN (Persero) RAYON MAKASSAR TIMUR, PENYULANG KIMA
}

\author{
Remigius Tandioga ${ }^{1}$, Musrady Mulyadi ${ }^{1}$, Tony Christianto E.S ${ }^{2}$, dan Ahmad Tegar $^{2}$
}

\begin{abstract}
Abstrak: Penelitian ini bertujuan untuk mengetahui seberapa besar persentase ketidakseimbangan beban pada transformator dan juga untuk mengetahui seberapa besar efisiensi dan rugi daya transformator pada saat diberi beban seimbang maupun tidak seimbang. Karena data yang terukur merupakan beban tidak seimbang maka untuk menghitung beban pada saat keadaan seimbang digunakan harga rata-rata dari data tersebut. Dengan menentukan faktor ketidakseimbangan lewat metode komponen simetris dan metode koefisien tak seimbang, maka didapatkan rugi tembaga, daya output dan efisiensi dalam keadaan tidak seimbang. Hasil penelitian ini menunjukkan bahwa pada saat transformator diberi beban tidak seimbang maka efisiensinya akan menurun dibandingkan dengan saat transformator diberi beban yang seimbang. Akan tetapi ketidakseimbangan beban tidak terlalu berpengaruh terhadap efisiensi karena memberikan perubahan efisiensi yang tidak terlalu signifikan yakni rata-rata sebesar $3,47 \%$ saja.
\end{abstract}

Kata Kunci : Transformator, Ketidakseimbangan, Beban

\section{PENDAHULUAN}

Energi listrik merupakan salah satu komponen terpenting untuk menunjang pembangunan suatu bangsa. Energi listrik mempunyai peranan penting dalam kehidupan manusia seiring dengan semakin meningkatnya pembangunan berbagai bidang dan tingkat kesejahteraan masyarakat maka laju konsumsi energi semakin meningkat pula. Walaupun demikian, tenaga listrik dapat pula membahayakan manusia dan berpotensi menimbulkan dampak negatif terhadap lingkungan hidup. Oleh karena itu, dalam pengelolaan sumber daya listrik hendaklah dilaksanakan secara andal, aman, dan ramah lingkungan. Oleh karena itu, untuk melayani seluruh daerah beban perlu dilakukan pemerataan pemakaian listrik secara tepat agar seluruh kondisi sistem dapat terjaga keseimbangannya. Selain itu, secara operasional juga harus mampu mengimbangi kondisi dinamis perubahan beban ini menyebabkan pasokan daya listrik harus benar-benar terjaga dan cukup untuk melayani semua beban yang tersebar di setiap titik pusat beban. Salah satu peralatan yang sangat penting dalam penyaluran energi listrik yaitu transformator. Pada umumnya beban yang dilayani suatu transformator pada suatu sistem distribusi diusahakan agar tetap seimbang, tetapi dalam kenyataannya sering terjadi ketidakseimbangan beban. Ketidakseimbangan beban yang terjadi pada tiap-tiap fasa (fasa $R$, fasa $S$ dan fasa T) ini menyebabkan arus beban berubah-ubah maka rugi-rugi tembaga juga berubah. Semakin besar ketidakseimbangan beban suatu transformator maka rugi daya yang ditimbulkan juga akan semakin besar sehingga efisiensi dari transformator tersebut akan menurun. Menurunnya efisiensi suatu transformator akan mempengaruhi kinerjanya dalam mensuplai daya listrik kepada konsumen, karena kapasitas daya yang seharusnya dapat disalurkan oleh transformator sebagian besar menjadi rugi daya yang hilang menjadi panas. Panas yang tinggi juga dapat merusak transformator.Melihat dari data pengukuran beban transformator pada triwulan 4 tahun 2014 oleh pihak PLN untuk Penyulang UNHAS, besar arus beban tidak sama besar setiap fasa yang menandakan ketidakseimbangan beban antar fasa. Maka dari data pada Penyulang UNHAS, kami berpendapat jika di UNHAS mempunyai arus beban yang besar dan tidak sama besar tiap fasanya, bagaimana dengan Penyulang Kima yang berupa kawasan industri yang menggunakan mesin-mesin berdaya besar, apakah mempunyai arus beban yang besar pula dan beda setiap fasa? Oleh karena itu berdasarkan latar belakang yang

\footnotetext{
${ }^{1}$ Staf Pengajar D4 Jurusan Teknik Mesin Politeknik Negeri Ujung Pandang

${ }^{2}$ Alumni Program D4 Jurusan Teknik Mesin Politeknik Negeri Ujung Pandang
} 
81 Remigius Tandioga, Musrady Mulyadi, Tony Christianto E.S, dan Ahmad Tegar. Analisis Pengaruh Ketidakseimbangan Beban Terhadap Efisiensi Transformator Tiga Fasa Di Pt. Pln (Persero) Rayon Makassar Timur, Penyulang Kima

dijelaskan di atas, Pada penulisan tugas akhir ini kami melakukan penelitian untuk melihatsejauh mana pengaruh sistem pembebanan tidak seimbang pada transformator, terhadapefisiensi transformator,dengan mengambil data serta informasi di PT. PLN (Persero) Rayon Timur, khususnya untuk Penyulang Kima.

\subsection{Transformator}

Transformator adalah suatu alat listrik yang dapat memindahkan dan mengubah energi listrik dari suatu atau lebih rangkaian listrik ke rangkaian listrik yang lain melalui suatu gandengan magnet dan berdasarkan prinsip induksi-elektromagnetik (Yon Rijono, 1997). Transformator digunakan secara luas, baik dalam bidang tenaga listrik maupun elektronika. Penggunaannya dalam sistem tenaga memungkinkan dipilihnya tegangan yang sesuai dan ekonomis untuk tiap-tiap keperluan; misalnya, kebutuhan akan tegangan tinggi dalam pengiriman daya listrik jarak jauh. Dalam bidang elektronika, transformator digunakan antara lain sebagai gandengan impendansi antara sumber dan beban; untuk memisahkan satu rangkaian dari rangkaian yang lain; untuk menghambat arus searah sambil tetap melakukan arus bolak-balik antara rangkaian.

Prinsip kerja transformator adalah berdasarkan hukum Faraday yaitu arus listrik dapat menimbulkan medan magnet dan sebaliknya medan magnet dapat menimbulkan arus listrik. Bila pada salah satu kumparan transformator, yakni primer,diberi arus listrik bolak-balik, maka sebuah fluks bolak balik akan dihasilkanyang amplitudonya akan bergantung pada tegangan primer dan banyaknya lilitan. Kumparan sekunder juga menerima fluks magnet dari kumparan primer yang jumlahnya juga berubah. Maka pada kumparan sekunder juga timbul induksi dan akibatnya antara dua ujung kumparan terdapat beda tegangan (A.E. Fitzgerald,dkk. 1981).

keadaan yang tidak seimbang adalah keadaan dimana salah satu atau kedua syarat keadaan seimbang tidak terpenuhi. Dimana yang dimaksud dengan keadaan seimbang adalah suatu keadaan dimana :

$\checkmark$ Ketiga vektor arus dan tegangan sama besar

$\checkmark$ Ketiga vektor saling membentuk sudut $120^{\circ}$ satu sama lain.

Faktor ketidakseimbangan beban dapat ditentukan dengan dua cara. Yang pertama yaitu dengan metode komponen simetris yang didefinisikan sebagai perbandingan antara nilai komponen urutan negatif dengan komponen urutan positif. Komponen urutan positif, terdiri dari tiga fasor yang sama besarnya dan berbeda sudut fasanya $120^{\circ}$ dan mempunyai urutan yang sama dengan fasa aslinya. Sedangkan komponen urutan negatif, terdiri dari tiga fasor yang sama besarnya dan berbeda sudut fasanya $120^{\circ}$ dan mempunyai fasa urutan yang berlawanan dengan fasa aslinya (William D. Stevenson, 1997).

\subsection{Efisiensi}

Efisiensi pada transformator adalah perbandingan antara daya keluaran (output) dengan daya masukan (input). Sebuah transformator tidak membutuhkan bagian yang bergerak untuk memindahkan energi dari kumparan primer ke kumparan sekunder. Ini berarti tidak ada kerugian karena gesekan atau hambatan udara seperti yang terdapat pada mesin - mesin listrik (contoh motor listrik dan generator). Namun di dalam transformator juga terdapat kerugian yang disebut rugi-rugi tembaga (copper losses) dan rugi-rugi besi (iron losses). Rugi-rugi tembaga terdapat pada kumparan primer dan kumparan sekunder, sedangkan rugi-rugi besi terdapat dalam inti besi. Rugi-rugi ini berupa panas yang dilepaskan akibat terjadinya Eddy current. Sebuah transformator yang ideal akan memiliki efisiensi sebesar $100 \%$. Ini berarti bahwa semua daya yang diberikan pada kumparan primer dipindahkan ke kumparan sekunder tanpa adanya kerugian. Sebuah transformator yang real memiliki efisiensi di 
bawah 100\%. Untuk transformator yang bekerja pada tegangan dan frekuensi yang konstan, efisiensinya dapat mencapai $98 \%$. berikut:

Dalam keadaan seimbang dan tidak seimbang efisiensi suatu transformator dinyatakan sebagai

$$
\begin{aligned}
\eta=\frac{\mathrm{P}_{\mathrm{o}}}{\mathrm{P}_{\mathrm{i}}} \times 100 \% & =\frac{\mathrm{P}_{\mathrm{o}}}{\mathrm{P}_{\mathrm{o}}+\Delta \mathrm{P}_{\mathrm{o}}+\Delta \mathrm{P}_{3 \emptyset}} \times 100 \% \eta^{\prime}=\frac{\mathrm{P}_{\mathrm{o}}^{\prime}}{\mathrm{P}_{\mathrm{i}}} \times 100 \% \\
= & \frac{\mathrm{P}_{\mathrm{o}}^{\prime}}{\mathrm{P}_{\mathrm{o}}^{\prime}+\Delta \mathrm{P}_{\mathrm{o}}+\Delta \mathrm{P}_{3 \emptyset}^{\prime}} \times 100 \%
\end{aligned}
$$

\section{METODE PENELITIAN}

\subsection{Objek Penelitian}

Dalam hal ini penyusun akan melakukan penelitian mengenai pengaruh beban tidak seimbang terhadap efisiensi transformator tiga phasa di PT. PLN (Persero) Rayon Makassar Timur, Penyulang Kima.

\subsection{Prosedur Penelitian}

Adapun prosedur dalam melakukan penelitian ini adalah sebagai berikut :

1. Melakukan survey lapangan pada lokasi PT. PLN (Persero) Rayon Makassar Timur, Penyulang Kima.

2. Mengambil data - data yang diperlukan untuk melakukan penelitian.

3. Melakukan penelitian tentang pengaruh beban tidak seimbang pada transformator 3 phasa.

4. Membuat analisis dari data-data yang telah diperoleh pada penelitian.

Setelah semuanya rampung maka penelitian selesai.

\subsection{Metode Analisis Data}

Untuk menganalisis hasil data yang diperoleh pada penelitian ini, maka dilakukan perhitungan dengan menggunakan rumus-rumus yang telah dipelajari baik pada saat kuliah maupun melalui studi literatur. Langkah-langkah perhitungannya sebagai berikut:
a. Menentukan persentase ketidakseimbangan beban.
b. Menentukan rugi tembaga untuk beban seimbang dan tidak seimbang.
c. Menentukan rugi daya untuk beban seimbang dan tidak seimbang.
d. Menentukan efisiensi transformator untuk beban seimbang dan tidak seimbang.
e. Menentukan perubahan rugi daya akibat beban tidak seimbang.

\section{HASIL DAN PEMBAHASAN}

3.1. Hasil

\section{Data Transformator di Lokasi}

Data transformator di lokasi yang diukur selama tiga puluh hari dapat dilihat pada Lampiran 1.

\section{Data Rugi-rugi Transformator}

Data rugi tanpa beban/rugi inti besi $\left(\Delta \mathrm{P}_{\mathrm{o}}\right)$ dan rugi tembaga beban penuh $\left(\Delta \mathrm{P}_{3 \phi(\mathrm{FL})}\right)$ masing-masing tercantum pada kolom 5 dan 6 pada Tabel 3.1:

Tabel 3.1 Rugi-rugi pada transformator

\begin{tabular}{|c|c|c|c|c|c|}
\hline \multirow{2}{*}{ No } & \multirow{2}{*}{ Kode gardu } & Lokasi & Kapasitas & \multicolumn{2}{|c|}{ Rugi-rugi } \\
\cline { 5 - 6 } & & $\mathrm{kVA})$ & $\Delta \mathrm{P}_{0}$ & $\Delta \mathrm{P}_{3 \phi(\mathrm{FL})}$ \\
\hline 1 & GT. IKM001 & Jl. Masuk GI Daya & 160 & 300 & 2000 \\
\hline 2 & GT. IKM002 & Kima 3 PT. Varia Usaha Beton & 200 & 355 & 2350 \\
\hline 3 & GT. IKM003 & Kima 4 & 100 & 210 & 1420 \\
\hline 4 & GT. IKM004 & Kima 4 & 50 & 125 & 800 \\
\hline 5 & GT. IKM005 & Kima 5 PT. Suntory Garuda & 160 & 300 & 2000 \\
\hline 6 & GT. IKM006 & Kima 9 PT. Calvindo Felix & 200 & 355 & 2350 \\
\hline 7 & GT. IKM007 & Kima 9 PT. Cahaya Cemerlang & 250 & 420 & 2750 \\
\hline
\end{tabular}


83 Remigius Tandioga, Musrady Mulyadi, Tony Christianto E.S, dan Ahmad Tegar. Analisis Pengaruh Ketidakseimbangan Beban Terhadap Efisiensi Transformator Tiga Fasa Di Pt. Pln (Persero) Rayon Makassar Timur, Penyulang Kima

\begin{tabular}{|l|l|c|c|c|c|}
\hline 8 & GT. IKM008 & Kima 9 & 250 & 420 & 2750 \\
\hline 9 & GT. IKM009 & Kima 9 & 250 & 420 & 2750 \\
\hline 10 & GT. IKM010 & Kantor Telkom & 160 & 300 & 2000 \\
\hline 11 & GT. IKM011 & Kantor Kima & 200 & 355 & 2350 \\
\hline
\end{tabular}

\subsection{Pembahasan}

Dengan mengambil contoh salah satu data transformator pada Tabel 3.2. berikut:

\begin{tabular}{|c|c|c|c|c|c|c|c|c|c|c|c|c|c|c|c|}
\hline \multirow{3}{*}{$\begin{array}{l}\text { No/Kode } \\
\text { Gardu }\end{array}$} & \multirow{3}{*}{ Lokasi } & \multicolumn{10}{|c|}{ Data Pengukuran } & \multirow{2}{*}{\multicolumn{4}{|c|}{$\begin{array}{c}\text { Data Trafo } \\
\text { Beban (kVA) }\end{array}$}} \\
\hline & & \multicolumn{4}{|c|}{ Arus (A) } & \multicolumn{6}{|c|}{ Tegangan (V) } & & & & \\
\hline & & $\mathbf{R}$ & $\mathrm{S}$ & $\mathbf{T}$ & $\mathrm{N}$ & R-S & S-T & T-R & R-N & S-N & T-N & $\mathbf{R}$ & $\mathrm{S}$ & $\mathbf{T}$ & $\%$ \\
\hline GT. IKM001 & Л. Masuk GI Daya & 48,2 & 58 & 59 & 19 & 385 & 396 & 394 & 220 & 227 & 228 & 10,60 & 13,17 & 13,45 & 23,26 \\
\hline GT. IKM002 & $\begin{array}{c}\text { Kima } 3 \text { PT. Varia } \\
\text { Ussha Beton }\end{array}$ & 70,5 & 60,2 & 62 & 7,8 & 392 & 398 & 393 & 225 & 227 & 227 & 15,86 & 13,67 & 14,07 & 21,80 \\
\hline GT. IKM003 & Kima 4 & 75,5 & 36,1 & 37 & 36 & 398 & 398 & 398 & 218 & 226 & 224 & 16,46 & 8,16 & 8,29 & 32,91 \\
\hline GT. IKM004 & Kima 4 & 7,6 & 4,31 & 6 & 0,64 & 398 & 395 & 393 & 228 & 229 & 226 & 1,73 & 0,99 & 1,36 & 8,15 \\
\hline GT. IKM005 & $\begin{array}{c}\text { Kima } 5 \text { PT. Suntory } \\
\text { Garuda }\end{array}$ & 13,1 & 22 & 10,8 & 12,2 & 397 & 393 & 392 & 227 & 230 & 224 & 2,97 & 5,06 & 2,42 & 6,53 \\
\hline GT. IKM006 & $\begin{array}{c}\text { Kima } 9 \text { PT. } \\
\text { Calvindo Felix }\end{array}$ & 22,8 & 21,9 & 25,5 & 9,2 & 402 & 485 & 395 & 235 & 263 & 252 & 5,36 & 5,76 & 6,43 & 8,77 \\
\hline GT. IKM007 & $\begin{array}{c}\text { Kima } 9 \text { PT. Cahaya } \\
\text { Cemerlang }\end{array}$ & 36 & 33,8 & 37,2 & 7,2 & 417 & 410 & 414 & 240 & 245 & 241 & 8,64 & 8,28 & 8,97 & 10,35 \\
\hline GT. IKM008 & Kima 9 & 92 & 88,5 & 99 & 15,2 & 388 & 394 & 396 & 224 & 226 & 225 & 20,61 & 20,00 & 22,28 & 25,15 \\
\hline GT. IKM009 & Kima 9 & 192 & 200 & 180 & 25,8 & 388 & 384 & 378 & 211 & 222 & 215 & 40,51 & 44,40 & 38,70 & 49,44 \\
\hline GT. IKM010 & Kantor Telkom & 49,3 & 82 & 85,2 & 85 & 400 & 393 & 398 & 231 & 237 & 226 & 11,39 & 19,43 & 19,26 & 31,30 \\
\hline GT. IKM011 & Kantor Kima & 45 & 59,4 & 55,1 & 26 & 400 & 395 & 399 & 231 & 229 & 229 & 10,40 & 13,60 & 12,62 & 18,31 \\
\hline
\end{tabular}

\section{Persentase Ketidakseimbangan Beban dengan Metode Komponen Simetris}

Berdasarkan data tabel diatas untuk GT. IKM002 hari ke-1, $\mathrm{I}_{\mathrm{R}}=70,5 \mathrm{~A}, \mathrm{I}_{\mathrm{S}}=60,2 \mathrm{~A}$, dan $\mathrm{I}_{\mathrm{T}}=62$ A, faktor ketidakseimbangan bebannya $\left(\mathrm{U}_{\mathrm{FI}}\right)$ dapat dilihat pada analisis berikut :

$$
\begin{aligned}
\boldsymbol{I}_{\boldsymbol{R} \boldsymbol{I}} & =\frac{\mathbf{1}}{3}\left(\boldsymbol{I}_{\boldsymbol{R}}+\boldsymbol{a} \boldsymbol{I}_{S}+\boldsymbol{a}^{2} \boldsymbol{I}_{T}\right) \\
& =\frac{1}{3}\left((70,5)+\left(1 \angle 120^{\circ}\right)\left(60,2 \angle 240^{\circ}\right)+\left(1 \angle 240^{\circ}\right)\left(62 \angle 120^{\circ}\right)\right) \\
& =\frac{1}{3}(70,5+60,2+62) \\
& =\frac{1}{3}(192,7) \\
\boldsymbol{I}_{\boldsymbol{R} I} & =64,23 \angle 0^{\circ} \\
\mathrm{I}_{\mathrm{R} 1} & =64,23 \\
\boldsymbol{I}_{\boldsymbol{R} 2} & =\frac{\mathbf{1}}{3}\left(\boldsymbol{I}_{\boldsymbol{R}}+\boldsymbol{a}^{2} \boldsymbol{I}_{\boldsymbol{S}}+\boldsymbol{a} \boldsymbol{I}_{T}\right) \\
& =\frac{1}{3}\left((70,5)+\left(1 \angle 240^{\circ}\right)\left(60,2 \angle 240^{\circ}\right)+\left(1 \angle 120^{\circ}\right)\left(62 \angle 120^{\circ}\right)\right) \\
& =\frac{1}{3}\left((70,5)+\left(60,2 \angle 120^{\circ}\right)+\left(62 \angle 240^{\circ}\right)\right)
\end{aligned}
$$

$\boldsymbol{I}_{\boldsymbol{R} 2}=3,18 \angle-9,42^{\circ}$

$\mathrm{I}_{\mathrm{R} 2}=3,18$

Jadi, faktor ketidakseimbangan bebannya yaitu:

$$
\mathrm{U}_{\mathrm{FI}}=\frac{\mathrm{I}_{\mathrm{R}}}{\mathrm{I}_{\mathrm{R}}}=\frac{3,1}{6,2} \times 100=4,94 \%
$$

Selanjutnya perhitungan faktor ketidakseimbangan tegangan $\left(\mathrm{U}_{\mathrm{FV}}\right)$ berdasarkan data pada tabel diatas hari ke-1 untuk GT. IKM002, $\mathrm{V}_{\mathrm{R}-\mathrm{N}}=225 \mathrm{~V}, \mathrm{~V}_{\mathrm{S}-\mathrm{N}}=227 \mathrm{~V}$, dan $\mathrm{V}_{\mathrm{T}-\mathrm{N}}=228 \mathrm{~V}$ adalah berikut :

$$
\begin{aligned}
V_{\boldsymbol{R} \boldsymbol{I}} & =\frac{\mathbf{1}}{3}\left(\boldsymbol{V}_{\boldsymbol{R}}+\boldsymbol{a} \boldsymbol{V}_{\boldsymbol{S}}+\boldsymbol{a}^{2} \boldsymbol{V}_{T}\right) \\
& =\frac{1}{3}\left((225)+\left(1 \angle 120^{\circ}\right)\left(227 \angle 240^{\circ}\right)+\left(1 \angle 240^{\circ}\right)\left(227 \angle 120^{\circ}\right)\right) \\
& =\frac{1}{3}(225+227+227)
\end{aligned}
$$

DOI : http://dx.doi.org/10.31963/sinergi.v16i1.1205 


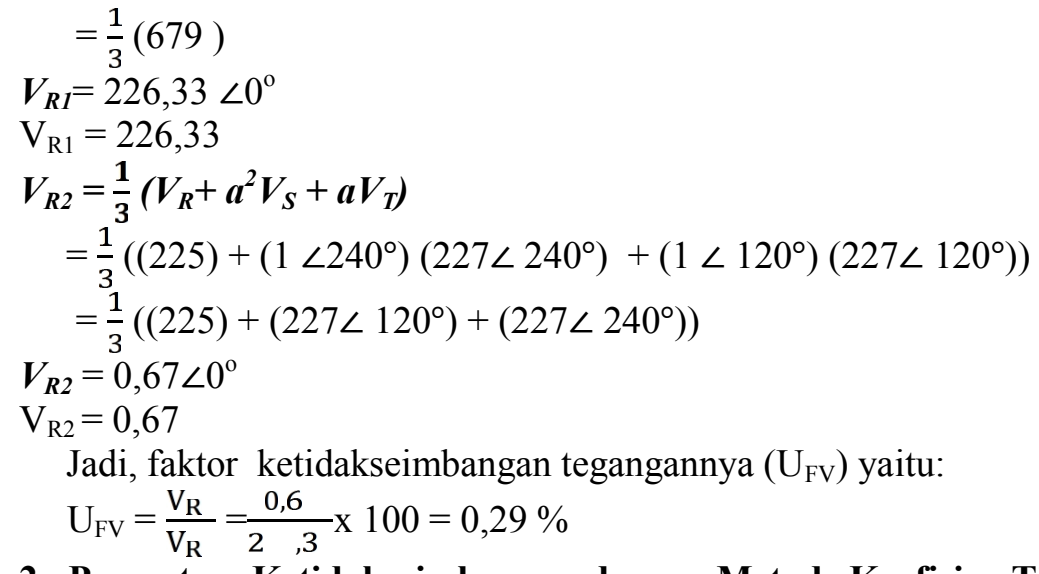

\section{Persentase Ketidakseimbangan dengan Metode Koefisien Tidak Seimbang}

Perhitungan faktor ketidakseimbangan juga dapat diselesaikan dengan menggunakan persamaan (215), (2-16), (2-17), (2-18) dan (2-20) yang juga berlaku untuk tegangan.

a. Arus

$$
\begin{aligned}
& \overline{\mathrm{I}}=\frac{\mathrm{I}_{\mathrm{R}}+\mathrm{I}_{\mathrm{S}}+\mathrm{I}_{\mathrm{T}}}{3}=\frac{7,5+6,2+6}{3}=64,23 \mathrm{~A} \\
& \mathrm{a}_{1}=\frac{\mathrm{I}_{\mathrm{R}}}{\overline{\mathrm{I}}}=\frac{7,5}{6,2}=1,1 \\
& \mathrm{~b}_{1}=\frac{\mathrm{I}_{\mathrm{S}}}{\overline{\mathrm{I}}}=\frac{6,2}{6,2}=0,94 \\
& \mathrm{c}_{1}=\frac{\mathrm{I}_{\mathrm{T}}}{\overline{\mathrm{I}}}=\frac{6}{6,2}=0,97 \\
& \mathrm{U}_{\mathrm{F}}=\frac{(|\mathrm{a}-1|+|\mathrm{b}-1|+|\mathrm{c}-1|)}{3} \mathrm{x} 100 \% \\
& U_{F}=\frac{(|1,0-1|+|0,9-1|+|0,9-1|)}{3} \times 100 \% \\
& =6,5 \% \\
& \bar{V}=\frac{V_{R}+V_{S}+V_{T}}{3}=\frac{2+2+2}{3}=226,33 \mathrm{~V} \\
& \mathrm{a}_{2}=\frac{\mathrm{I}_{\mathrm{R}}}{\overline{\mathrm{I}}}=\frac{2}{2,3}=0,99 \\
& \mathrm{~b}_{2}=\frac{\mathrm{I}_{\mathrm{S}}}{\overline{\mathrm{I}}}=\frac{2}{2,3}=1,0 \\
& \mathrm{c}_{2}=\frac{\mathrm{I}_{\mathrm{T}}}{\overline{\mathrm{I}}}=\frac{2}{2,3}=1,0 \\
& \mathrm{U}_{\mathrm{FV}}=\frac{(|\mathrm{a}-1|+|\mathrm{b}-1|+|\mathrm{c}-1|)}{3} \mathrm{x} 100 \% \\
& \mathrm{U}_{\mathrm{FV}}=\frac{(|0,9-1|+|1,0-1|+|1,0-1|)}{3} \mathrm{x} 100 \% \\
& =0,39 \%
\end{aligned}
$$

\section{Menghitung Rugi Tembaga dengan Metode Koefisien Tidak Seimbang}

Pada perhitungan rugi tembaga diambil data pada ke-1 untuk GT. IKM002, serta data pada Tabel 4.1 Rugi daya tembaganya dapat dilihat pada analisis berikut :

$\mathrm{S}=\sqrt{3} \mathrm{~V}_{\mathrm{p}(\mathrm{LL})} \mathrm{I}_{\mathrm{p}}$

$\mathrm{I}_{\mathrm{p}(\mathrm{FL})}=\frac{\mathrm{S}}{\sqrt{3} \mathrm{~V}_{\mathrm{p}}}=\frac{2}{\sqrt{3} 2}=5,77 \mathrm{~A}$

$\mathrm{S}=\sqrt{3} \mathrm{~V}_{\mathrm{s}(\mathrm{LL})} \mathrm{I}_{\mathrm{S}}$

$\mathrm{I}_{\mathrm{sec}(\mathrm{FL})}=\frac{S}{\sqrt{3} V_{S(L)}}=\frac{2}{\sqrt{3} 4}=288,675 \mathrm{~A}$ 
85 Remigius Tandioga, Musrady Mulyadi, Tony Christianto E.S, dan Ahmad Tegar. Analisis Pengaruh Ketidakseimbangan Beban Terhadap Efisiensi Transformator Tiga Fasa Di Pt. Pln (Persero) Rayon Makassar Timur, Penyulang Kima

Jika I merupakan arus sekunder rata-rata dan $\Delta \mathrm{P}_{3 \phi}$ merupakan rugi-rugi tembaga pada berbagai keadaan, maka :

$$
\begin{aligned}
& \Delta \mathrm{P}_{3 \emptyset}=\frac{\overline{\mathrm{I}}^{2}}{\mathrm{I}_{\mathrm{S}}^{2}(\mathrm{~F})} \times \Delta \mathrm{P}_{3 \phi(\mathrm{F})} \\
& \begin{aligned}
\Delta \mathrm{P}_{3 \phi} & =\frac{\left(\frac{7,5+6,2+6}{3}\right)^{2}}{2,62} \times 2350 \\
& =116,35 \mathrm{Watt}
\end{aligned}
\end{aligned}
$$

Dengan menggunakan persamaan (2-53) dapat dihitung rugi tembaga dalam keadaan tidak seimbang seperti di bawah ini :

$$
\begin{aligned}
\Delta \mathrm{P}_{3 \emptyset}^{\prime} & =\mathrm{M}_{\mathrm{F} . \Delta \mathrm{P}_{3 \phi}} \\
& =\frac{a_{1}^{2}+b_{1}^{2}+c_{1}^{2}}{3} \cdot \Delta \mathrm{P}_{3 \phi} \\
& =\frac{1,1^{2}+0,9^{2}+0,9^{2}}{3} \cdot 116,35 \\
& =116,92^{3} \mathrm{~W}
\end{aligned}
$$

\section{Menghitung Rugi Daya Total}

Perubahan nilai rugi daya total adalah hasil pengurangan dari nilai rugi daya total tidak seimbang dengan nilai rugi daya total seimbang.

$$
\begin{aligned}
& \text { a. Pada keadaan seimbang } \\
& \begin{aligned}
\Delta \mathrm{P} & =\Delta \mathrm{P}_{0}+\Delta \mathrm{P}_{3 \phi} \\
& =355 \mathrm{~W}+116,35 \mathrm{~W} \\
& =471,35 \mathrm{~W}
\end{aligned}
\end{aligned}
$$

\section{b. Pada keadaan tidak seimbang}

$$
\begin{aligned}
& \Delta \mathrm{P}^{\prime}=\Delta \mathrm{P}_{0}+\Delta \mathrm{P}_{3 \emptyset}^{\prime} \\
& =355 \mathrm{~W}+116,92 \mathrm{~W} \\
& =471,92 \mathrm{~W}
\end{aligned}
$$

Setelah didapatkan nilai rugi daya total baik keadaan seimbang maupun tidak seimbang maka juga dapat didapatkan perubahan rugi daya totalnya.

$$
\begin{aligned}
\Delta \mathrm{P}^{\prime}-\Delta \mathrm{P}=\Delta \mathrm{P}^{\prime}- & \Delta \mathrm{P} \\
& =471,92-471,35 \\
& =0,57 \text { Watt }
\end{aligned}
$$

\section{Efisiensi}

Pada perhitungan efisiensi transformator digunakan persamaan (2-60) dan (2-61) untuk keadaan seimbang dan tidak seimbang, tapi sebelum menghitung efisiensinya terlebih dahulu dihitung daya keluarannya.

$$
\begin{aligned}
& \text { a. Pada keadaan seimbang } \\
& \begin{aligned}
\mathrm{P}_{\text {out }} & =3 \overline{\mathrm{V}} \overline{\mathrm{I}} \cos \phi \\
& =3.226,33.64,23.0,85 \\
& =37,072 \mathrm{~kW}=37072 \mathrm{Watt}
\end{aligned} \\
& \begin{aligned}
\eta=\frac{\mathrm{P}_{0}}{\mathrm{P}_{0}+\Delta \mathrm{P}} \times 100 \% \\
=\frac{3.0}{3.0+4.3} \times 100 \%
\end{aligned}
\end{aligned}
$$

DOI : http://dx.doi.org/10.31963/sinergi.v16i1.1205 
$=98,74 \%$

b. Pada keadaan tidak seimbang

$\mathrm{P}_{\mathrm{o}}^{\prime}=\left(\mathrm{a}_{2} \cdot \mathrm{a}_{1}+\mathrm{b}_{2} \cdot \mathrm{b}_{1}+\mathrm{c}_{2} \cdot \mathrm{c}_{1}\right) \overline{\mathrm{V}} \overline{\mathrm{I}} \cos \phi$

$=((0,99.1,10)+(1.0,94)+(1.0,97)) 226,33.64,23.0,85$

$=13,485 \mathrm{~kW}=13.485 \mathrm{Watt}$

$$
\begin{gathered}
\eta^{\prime}=\frac{\mathrm{P}_{0}^{\prime}}{\mathrm{P}_{0}^{\prime}+\Delta \mathrm{P}^{\prime}} \times 100 \% \\
=\frac{1.4}{1.4+4 \quad, 9} \times 100 \% \\
=96,62 \%
\end{gathered}
$$

\begin{tabular}{|c|c|c|c|c|c|c|}
\hline \multicolumn{6}{|c|}{ GT.IKM002 } & \multirow[b]{3}{*}{ Hari } \\
\hline \multicolumn{3}{|c|}{ Metode komponen simetris } & \multicolumn{3}{|c|}{ Metode koefisien tidak seimbang } & \\
\hline $\mathrm{U}_{\mathrm{FI}}(\%)$ & $\eta(\%)$ & $\eta^{\prime}(\%)$ & $U_{F I}(\%)$ & $\eta(\%)$ & $\eta^{\prime}(\%)$ & \\
\hline 0,84 & 98,8 & 96,45 & 1,07 & 98,8 & 96,45 & 7 \\
\hline 0,93 & 98,82 & 96,65 & 1,11 & 98,82 & 96,65 & 9 \\
\hline 1,1 & 98,84 & 96,59 & 1,46 & 98,84 & 96,59 & 12 \\
\hline 1,13 & 98,82 & 96,44 & 1,35 & 98,82 & 96,44 & 2 \\
\hline 1,13 & 98,86 & 96,72 & 1,37 & 98,86 & 96,72 & 10 \\
\hline 1,22 & 98,85 & 96,76 & 1,49 & 98,85 & 96,76 & 6 \\
\hline 1,63 & 98,83 & 96,55 & 1,97 & 98,83 & 96,55 & 8 \\
\hline 2 & 98,84 & 96,75 & 2,45 & 98,84 & 96,75 & 15 \\
\hline 2,04 & 98,86 & 96,77 & 2,67 & 98,86 & 96,77 & 11 \\
\hline 2,06 & 98,82 & 96,52 & 2,49 & 98,82 & 96,52 & 3 \\
\hline 2,13 & 98,86 & 96,6 & 2,49 & 98,86 & 96,6 & 13 \\
\hline 2,52 & 98,82 & 96,44 & 3,33 & 98,82 & 96,44 & 4 \\
\hline 3,23 & 98,76 & 96,59 & 4,3 & 98,76 & 96,59 & 14 \\
\hline 3,55 & 98,79 & 96,38 & 4,5 & 98,79 & 96,38 & 5 \\
\hline 4,39 & 98,75 & 96,63 & 5,75 & 98,75 & 96,63 & 22 \\
\hline 4,46 & 98,75 & 96,6 & 5,83 & 98,75 & 96,6 & 20 \\
\hline 4,53 & 98,75 & 96,59 & 5,8 & 98,75 & 96,59 & 21 \\
\hline 4,57 & 98,74 & 96,59 & 5,98 & 98,74 & 96,59 & 17 \\
\hline 4,59 & 98,76 & 96,65 & 6,09 & 98,76 & 96,65 & 19 \\
\hline 4,76 & 98,75 & 96,62 & 6,32 & 98,75 & 96,62 & 30 \\
\hline 4,8 & 98,75 & 96,63 & 6,16 & 98,75 & 96,63 & 28 \\
\hline 4,85 & 98,73 & 96,64 & 6,31 & 98,73 & 96,64 & 24 \\
\hline 4,94 & 98,74 & 96,62 & 6,5 & 98,74 & 96,62 & 1 \\
\hline 4,94 & 98,75 & 96,62 & 6,12 & 98,75 & 96,62 & 29 \\
\hline 4,98 & 98,74 & 96,61 & 6,62 & 98,74 & 96,61 & 18 \\
\hline 5,08 & 98,75 & 96,63 & 6,56 & 98,75 & 96,63 & 23 \\
\hline 5,08 & 98,75 & 96,63 & 6,53 & 98,75 & 96,63 & 26 \\
\hline 5,28 & 98,75 & 96,64 & 6,96 & 98,75 & 96,64 & 27 \\
\hline 5,33 & 98,75 & 96,64 & 6,98 & 98,75 & 96,64 & 25 \\
\hline 6,5 & 98,74 & 96,69 & 8,53 & 98,74 & 96,69 & 16 \\
\hline
\end{tabular}

Berikut adalah tabel 3.3. yang merupakan hasil perhitungan dan grafik untuk transformator GT.IKM002 selama 30 hari. 
87 Remigius Tandioga, Musrady Mulyadi, Tony Christianto E.S, dan Ahmad Tegar. Analisis Pengaruh Ketidakseimbangan Beban Terhadap Efisiensi Transformator Tiga Fasa Di Pt. Pln (Persero) Rayon Makassar Timur, Penyulang Kima

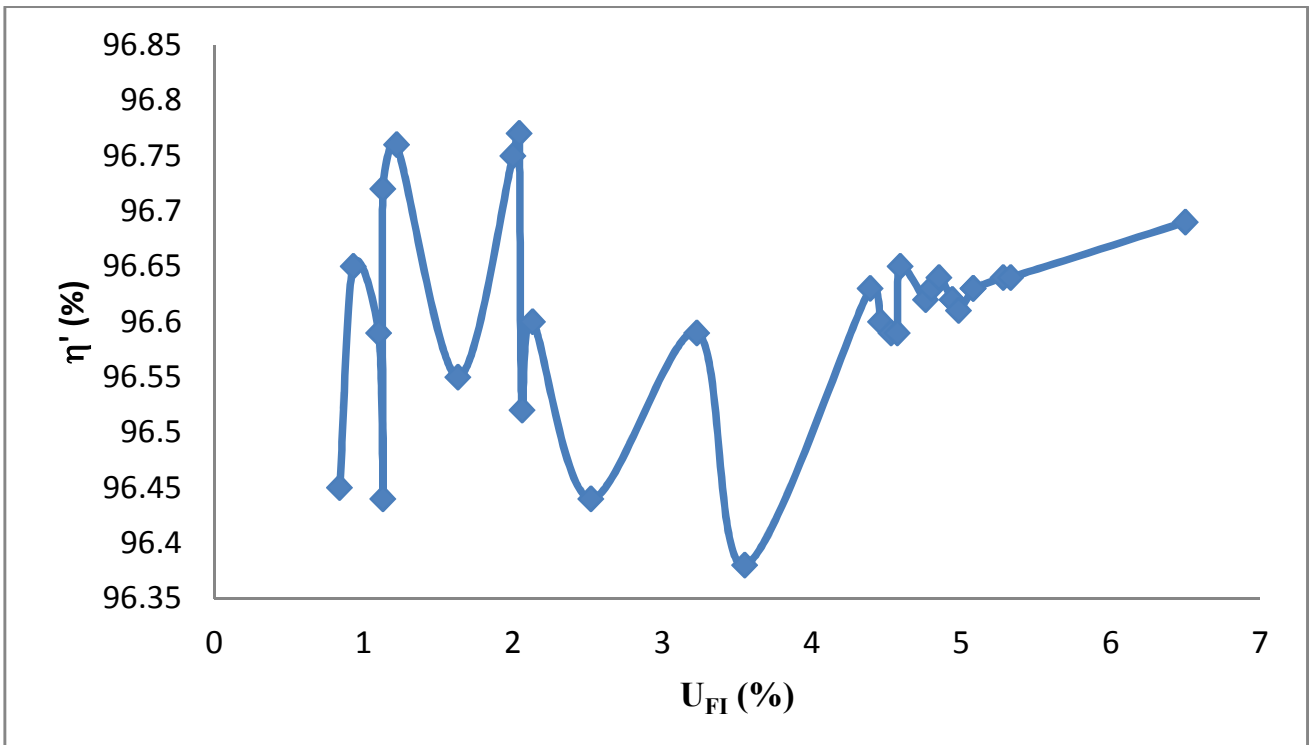

Gambar 1. Hubungan antara faktor ketidakseimbangan metode komponen simetris $\left(U_{F I}\right)$ dan efisiensi ( $\eta$ ') untuk GT.IKM002

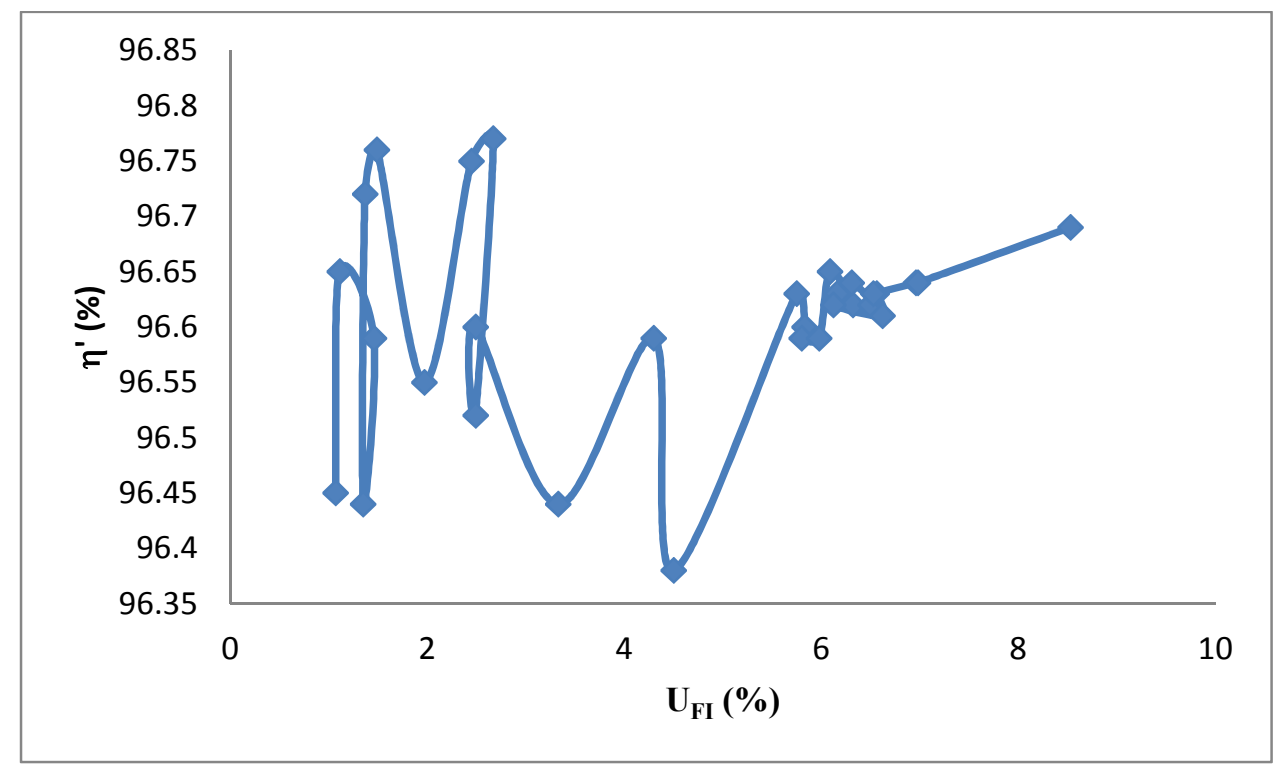

Gambar 2. Hubungan antara faktor ketidakseimbangan metode koefisien tak seimbang $\left(U_{\mathrm{FI}}\right)$ dan efisiensi ( $\eta$ ') untuk GT.IKM002

\section{KESIMPULAN}

Dari hasil pembahasan pada bab sebelumnya maka kami mengambil kesimpulan sebagai berikut:

1. Total rata-rata persentase ketidakseimbangan pada transformator dengan menggunakan metode komponen simetris untuk $\left(\mathrm{U}_{\mathrm{FI}}\right)$ yaitu sebesar 8,22 \% dan untuk $\left(\mathrm{U}_{\mathrm{FV}}\right)$ yaitu sebesar $1 \%$ sedangkan dengan menggunakan metode koefisien tak seimbang persentase ketidakseimbangan untuk $\left(\mathrm{U}_{\mathrm{FI}}\right)$ yaitu sebesar 10,58 \% dan untuk $\left(\mathrm{U}_{\mathrm{FV}}\right)$ yaitu sebesar 34,21\%. Ketidakseimbangan beban pada transformator terjadi karena penggunaan beban listrik yang tidak merata.

2. Total rata-rata efisiensi transformator saat beban seimbang pada Penyulang Kima sebesar 98,20\%. 
3. Total rata-rata efisiensi transformator saat beban tidak seimbang turun menjadi $94,79 \%$. Dari hasil tersebut dapat dilihat bahwa semakin besar ketidakseimbangan beban suatu transformator maka efisiensinya akan menurun. Menurunnya efisiensi suatu transformator akan mempengaruhi kinerjanya dalam mensuplai daya listrik kepada konsumen.

\section{DAFTAR PUSTAKA}

Fitzgerald, A.E., D.E. Higginbotham, A. Grabel. 1981. Dasar-dasar Elektroteknik. Jilid 2. Edisi kelima. Alih bahasa oleh Pantur Silaban, Ph.D. Jakarta : Erlangga.

Jurusan Teknik Elektro Fakultas Teknik Universitas Hasanuddin. Optimalisasi Pembebanan Transformator Distribusi dengan Penyeimbangan Beban. (Online), (http://journal.unnes.ac.id/sju/index.php/eduel/article/download/4254/3921(diakses September 2015).

Kadir, Abdul. 2010. Transformator. Jakarta : Universitas Indonesia (UI-Press).

Lister, E.C. 1984. Mesin dan Rangkaian Listrik. Alih bahasa oleh Ir. Drs. Hanapi Gunawan. Jakarta : Erlangga

Rijono, Yon. 1997. Dasar Teknik Tenaga Listrik (Edisi Revisi). Yogyakarta : Andi Yogyakarta.

Risal, S dan M. Harlanu. 2014. Studi Eksplorasi Arus pada Kawat Netral Akibat Ketidakseimbangan Arus Beban pada Unit Transformator Distribusi di Universitas Negeri Semarang, (Online), jilid 3, No. 2 (http://journal.unhas.ac.id/index.php/prostek/article/download/956/830), diakses 9 September 2015.

SPLN D3. 002-1. 2007. Spesifikasi Transformator Distribusi Bagian 1 : Transformator Fase Tiga, $20 \mathrm{k}-400 \mathrm{~V}$ dan Tranformator Fase Tunggal, 20kV-231V dan 20/ $\sqrt{3} \mathrm{kV}-231 \mathrm{~V}$. Jakarta: PT. PLN (Persero).

Stevenson, Jr, W.D. 1994. Analisis Sistem Tenaga Listrik. Edisi keempat. Alih bahasa oleh Ir. Kamala Idris. Jakarta : Erlangga.

Zuhal. 1993. Dasar Teknik Tenaga Listrik dan Elektronika Daya. Jakarta : PT. Gramedia Pustaka Utama. 